\title{
Da Grande Saúde. A Transvaloração Nietzschiana do Conceito de Saúde ${ }^{1}$
}

\author{
On the Great Health. Nietrsche's \\ Transvaluation of the Concept of Health
}

\section{Marta Faustino}

Instituto de Filosofia da Nova (IFILNOVA/FCSH), Lisboa, Portugal

\section{Resumo}

Saúde e doença são categorias fundamentais no pensamento de Nietzsche. Elas premeiam toda a sua obra e intermedeiam muitas das suas teses principais. Mais que isso, aquilo a que Nietzsche chamou "grande saúde" parece desempenhar um papel decisivo na sua tarefa de superação do niilismo e reabilitação da cultura ocidental. O presente artigo pretende elucidar a noção nietzschiana de "grande saúde" a partir de uma análise conceptual daquilo a que chamamos a transvaloração nietzschiana do conceito de saúde. Analisaremos a noção nietzschiana no contraste

1 O presente artigo expõe uma parte dos resultados apresentados na tese de doutoramento "Nietzsche e a Grande Saúde. Para uma Terapia da Terapia", defendida em 2013 na FCSH/UNL. Uma versão muito preliminar deste artigo pode ser encontrada em FAUSTINO (2010). 
com a definição oficial de saúde, operante não só na medicina, mas também em outras práticas terapêuticas, como as filosófico-morais da Antiguidade ou as religiosas, como o cristianismo. Sendo manifesta a prevalência e relevância do conceito no pensamento de Nietzsche, procuraremos ainda determinar o seu critério para a aferição de saúde ou doença na ausência de uma definição universal alternativa. Por último, avaliaremos o conteúdo conceptual específico da noção de "grande saúde", no contraste e/ ou continuidade com a sua concepção de saúde.

Palavras-chave: Saúde. Doença. Niilismo. Grande Saúde.

\section{Abstract}

Health and sickness are fundamental categories in Nietzsche's thought. They pervade his whole work and intermediate many of his most important thesis. Moreover, what Nietzsche called "great health" seems to play a decisive role in his task of overcoming nihilism and rehabilitating Western culture. The present article aims to elucidate Nietzsche's notion of "great health" through a conceptual analysis of what we call Nietzsche's transvaluation of the concept of health. We shall compare and contrast Nietzsche's own conception with the official definition of health, which is at work not only in medicine but also in other therapeutic practices, such as the moral-philosophical ones in Antiquity, or the religious ones, like Christianity. Given the evident relevance and prevalence of the concept in Nietzsche's thought, we shall also try to determine his criterion for the assessment of health or sickness in the absence of an alternative universal definition. Finally, we shall evaluate the specific conceptual content of the notion of "great health" in the contrast and/ or continuity with his conception of health.

Keywords: Health. Sickness. Nihilism. Great Health. 


\section{Introdução}

Se há coisa que salta à vista a qualquer leitor, mais ou menos experiente, da obra de Nietzsche, é a profusão de vocabulário e metáforas médicas utilizadas pelo autor. No contexto dos mais variados temas e domínios, sejam eles a estética, a filosofia, a ciência, a moral ou a religião, a política, ou mesmo a reflexão sobre si mesmo enquanto autor, os seus escritos estão invariavelmente impregnados de considerações e avaliações clínicas, de diagnósticos, de prescrições e indicações terapêuticas, seja relativamente a uma sociedade, a uma cultura, a uma ideologia ou a indivíduos particulares especialmente representativos de uma determinada época ou cultura, como sejam Sócrates, Schopenhauer ou Wagner. "Saúde” e "doença” apresentam-se, assim, como verdadeiros conceitos-chave na filosofia de Nietzsche, assumindo, com uma relevância que se vai intensificando e acentuando, a função de categorias gerais de avaliação que Nietzsche utiliza em substituição das antigas fórmulas morais para distinguir, avaliar e hierarquizar uma multiplicidade de fenómenos e de manifestações culturais, sejam elas colectivas ou individuais, contemporâneas ou antigas, em qualquer um dos domínios que tenha vindo a tratar. (Cf. AHERN 1995, p. 1 ss.) Na fase final do seu pensamento, os termos médicos multiplicam-se cada vez mais e a preocupação com as questões da saúde e da doença torna-se tão central para Nietzsche que quase podemos afirmar, com Malcolm Pasley, que a partir de um certo ponto não se encontra sequer outro tema ou assunto nos seus escritos, tendo este absorvido ou "engolido tudo o resto"2.

Uma tal profusão de vocabulário e de considerações médicas poderia ser ocasional ou tratar-se de mais uma estratégia retórica ou estilística, como tantas outras que se encontram de forma tão característica na filosofia de Nietzsche. Mas não parece ser esse o caso. Pelo contrário, tanto a sua concentração nas questões da saúde e da doença como a sua possível auto-interpretação como "médico da cultura" aquilo que consideramos ser, não só a preocupação central de todo o seu

2 Cf. PASLEY (1978, pp. 136-137). Tal observação parece, aliás, justificada pela afirmação de Nietzsche em Ecce Homo, segundo a qual, a partir de certo momento e devido aos imperativos da sua "tarefa", não praticou mais nada senão fisiologia, medicina e ciências naturais (cf. EH HH 3).

3 Cf. FP 1872/73 23[15]; FP 1833 30[8]. Cf. também GC Prefácio 2. Sobre Nietzsche como médico da cultura cf. SCHIPPERGES (1975); AHERN (1995); CHERLONEIX (2002); BILHERAN (2005).

Estudos Nietzsche, Curitiba, v. 5, n. 2, p. 257-286, jul./dez. 2014 
projecto filosófico, como, principalmente, uma viragem no que diz respeito à própria compreensão da filosofia e daquilo que deverá ser o seu objecto, o seu método e os seus objectivos. Mais concretamente, a "verdade", tal como tradicionalmente compreendida, deixa de ser o foco principal, o fio condutor, o fim último a alcançar, sendo precisamente a saúde, ou a promoção da vida e o florescimento do organismo que toma o seu lugar (cf. BM 4). Neste sentido, podemos dizer que a filosofia de Nietzsche se caracteriza, justamente, por um esforço de saúde - não só da sua própria saúde, cuja simultânea fragilidade e resistência desde cedo se entrelaçou com o seu próprio filosofar, mas principalmente da sua época, do seu tempo, da sua cultura, dos seus contemporâneos. Um "médico filosófico no sentido excepcional do termo" é precisamente aquele que, de acordo com a sua própria definição, tem de "perseguir o problema da saúde conjunta de um povo, de uma época, de uma raça, da humanidade" (GC Prefácio 2).

Nietzsche não se contenta, porém, com uma simples concepção de saúde, ou um discurso linear sobre o assunto, mas acrescenta ainda um elemento conceptual que não pode senão aumentar a complexidade, perturbação e perplexidade do leitor ou intérprete dos seus textos, nomeadamente, aquilo a que chama "a grande saúde" (die grosse Gesundheit). Apesar das suas parcas aparições ao longo de toda a sua obra (ao contrário da simples noção de saúde, que permeia com grande insistência, tanto as suas obras publicadas, como todo o espólio), a importância da "grande saúde" não deve ser desvalorizada: a expressão aparece sempre em contextos de extrema relevância e em associação clara com uma espécie de culminar de todo o projecto nietzschiano, seja pela sua relação com o seu "novo ideal" (GC 382, GM II 24), pela sua atribuição aos espíritos livres ou aos novos filósofos (cf. HH I Prefácio 4, GC 382), ou mesmo pela sua identificação com a figura de Zaratustra (EH ZA 2).

O presente artigo apresenta uma análise conceptual daquilo a que aqui chamamos a transvaloração nietzschiana do conceito de saúde, a partir da qual se tornará possível entrever os traços teóricos fundamentais da sua "grande saúde". Procuraremos fazê-lo contrastando, sempre que possível, o carácter revolucionário das suas concepções com a noção tradicional operante, não só na medicina, como em outras práticas terapêuticas, como as filosófico-morais da Antiguidade ou as religiosas, como o cristianismo. Apresentando-se a saúde como um dos conceitos fundamentais do pensamento de Nietzsche, este estudo permitirá clarificar aspectos importantes do seu 
projecto de reabilitação e elevação da cultura ocidental, ao mesmo tempo que poderá contribuir para os debates contemporâneos em torno da necessidade de alteração da definição oficial de saúde.

\section{A Transvaloração Nietzschiana do Conceito de Saúde}

De acordo com a definição da Organização Mundial de Saúde, "saúde é um estado de completo bem-estar físico, mental e social, e não simplesmente a ausência de doenças ou enfermidades" ". Formulada e adoptada em 1946, esta última definição universal, com a qual ainda hoje operamos, continua ainda a fazer eco de uma concepção de saúde tão antiga quanto o próprio Hipócrates, e da qual, para os nossos propósitos, importa aqui realçar algumas características fundamentais. ${ }^{5}$ Em primeiro lugar, a saúde passa por ser um conceito claramente definível e universalmente aplicável, de tal forma que, dependendo da consonância ou dissonância de qualquer indivíduo relativamente à definição, esse mesmo indivíduo pode ser determinado como saudável ou doente, independentemente das suas próprias características ou particularidades individuais. Em segundo lugar, de acordo com a definição corrente, a saúde é, por um lado, um estado relativamente estável ou permanente, que se pode alcançar e manter até que haja uma interrupção; por outro lado, este estado é caracterizado como um estado de equilíbrio ou "bem-estar" em todos os domínios do organismo (não apenas ao nível do corpo e da mente, mas inclusivamente na sua dimensão social); por último, este estado de equilíbrio opõe-se à doença e exclui-a terminantemente.

Dominando a compreensão usual que hoje temos da saúde, estas mesmas características fundamentais podem já ser encontradas, ainda que com a sua configuração particular, não só na medicina mas também no contexto das terapias morais ou filosóficas da Antiguidade, como o estoicismo ou o

4 Cf. Preâmbulo à Constituição da Organização Mundial de Saúde (OMS/WHO).

5 Para os nossos propósitos não é relevante fazer uma análise exaustiva do conceito de saúde e do seu desenvolvimento até ao momento actual, mas apenas destacar as características fundamentais desta concepção, que, tendo-se mantido presentes desde Hipócrates, viriam a ser contestadas pela concepção nietzschiana de saúde. Para uma excelente descrição e análise da evolução do conceito de saúde, desde Hipócrates aos dias de hoje, cf. em especial RAZAC (2006). Cf. também LONG (1990) e SCLIAR (2007).

Estudos Nietzsche, Curitiba, v. 5, n. 2, p. 257-286, jul./dez. 2014 
epicurismo, e, em parte, também em terapias religiosas, como a do cristianismo: todas elas operam com uma noção muito clara e universal do que é a saúde, em contraste com a qual qualquer indivíduo pode ser determinado como saudável ou doente; para todas elas o estado de saúde é compreendido como um estado de paz, calma ou tranquilidade interior, que pode ser alcançado e mantido com alguma estabilidade e permanência, ou até mesmo de forma definitiva; para todas elas a saúde é o contrário da doença e implica a sua total erradicação. Todos estes aspectos serão fortemente contestados por Nietzsche, no âmbito daquilo a que podemos chamar uma completa inversão ou transvaloração do conceito tradicional de saúde. ${ }^{6}$

\subsection{O Carácter Indefinível da Saúde}

Um dos primeiros e mais importantes elementos da crítica nietzschiana ao conceito tradicional de saúde diz respeito à própria possibilidade de definição de saúde, pelo menos se entendermos por definição o estabelecimento universal e irrestrito daquilo que uma coisa é, na sua essência, independentemente de quaisquer circunstâncias e particularidades individuais, ou de quaisquer variações acidentais, que, por mais que possam fazer uma coisa aparecer sob configurações mais ou menos diferentes, não alteram aquilo que ela é, diriam os metafísicos, "em si mesma". Ora, "uma saúde em si mesma" - como, de resto, todos os "em si” da metafísica - é coisa que, para Nietzsche, não existe, sendo esta a principal razão pela qual todas as tentativas de a determinar desta forma e, por conseguinte, todas as tentativas de terapia assentes numa tal determinação, não puderam e não podem senão estar votadas ao fracasso (cf. GC 120).

Com efeito, e ao contrário do pressuposto fundamental de qualquer prática terapêutica, incluindo a nossa medicina actual, a saúde é algo de absolutamente individual": ela depende, nas palavras de Nietzsche, "do teu objectivo, do teu horizonte, das tuas forças, das tuas impulsões, dos teus erros e, especialmente, dos ideais e dos fantasmas da tua alma" (GC 120), ou seja, da absoluta singularidade de cada um, pelo que o número de saúdes

6 Cf. LONG (1990). Cf. também FAUSTINO (2010).

7 Cf. GC 120. Cf. também HH I 286: "Com a liberdade de opiniões passa-se o mesmo que com a saúde: ambas são individuais, de nenhuma se pode formular um conceito universalmente válido.” 
possíveis é, na verdade, equivalente ao número total de indivíduos e, portanto, potencialmente infinito. Longe de ser um conceito absoluto, fixo e inalterável, passível de ser trazido a uma definição geral e universalmente aplicável, a saúde deve, pois, ser pensada como um conceito fluido, profundamente relativo a e dependente de cada organismo, de tal forma que aquilo que constitui a saúde para um organismo pode perfeitamente significar a doença para outro, tal como, pela mesma lógica, aquilo que promove a saúde de um indivíduo pode muito bem provocar o adoecimento de outro (cf. GC 120, HH I 286). Por ser algo de tão individual e pessoal a saúde é, pois, do ponto de vista nietzschiano, absolutamente indefinível e indeterminável (idem).

Uma perspectiva contrária pressupõe, desde logo, o "dogma" (GC 120) da igualdade entre os homens, um dos preconceitos que, como se sabe, Nietzsche mais fortemente ataca ao longo de toda a sua obra, especialmente no que diz respeito à moral, que o usa como principal instrumento ao serviço da domesticação, tipificação e uniformização dos homens ou, na expressão preferida de Nietzsche, do seu "rebanho". ${ }^{8}$ Pressuposta está - seja no âmbito da moral, seja no âmbito da saúde, seja ainda no entrecruzamento entre ambas promovido pelos discursos morais e religiosos - a ideia de que, sendo os homens essencialmente iguais e apenas acidentalmente semelhantes, aquilo que beneficia o todo deverá também beneficiar toda a gente, isto é, cada indivíduo, em particular. Mas porque os homens não são iguais, nem tão-pouco se devem torná-lo - assim falava Zaratustra! (ZA Das Tarântulas) -, da perspectiva nietzschiana o que se passa é exactamente o contrário, sendo que o que é bom para as massas raramente ou nunca o é para o indivíduo enquanto tal, no sentido em que tolhe a sua individualidade e, em última análise, a suprime.

Todos os sistemas morais que reivindiquem aplicabilidade universal são, pois, "barrocos e irracionais - porque se dirigem a "todos", porque generalizam onde não se pode generalizar" (BM 198). Sendo cada indivíduo um acontecimento absolutamente singular e irrepetível, os seus valores ou virtudes deverão, igualmente, ser absolutamente individuais e singulares, completamente relativos a cada organismo, adaptados à sua história, aos seus objectivos, aos seus defeitos, à sua personalidade e às suas características particulares, e desenhados para promover o seu próprio crescimento ou florescimento individual; em caso contrário não podem senão ser-lhe

8 Cf. por exemplo GC 116; BM 199, 201; GM II 1, 2. 
prejudiciais: "uma virtude", escreve Nietzsche, "tem de ser uma invenção nossa, a nossa auto-defesa e necessidade mais pessoais: em qualquer outro sentido, ela é apenas um perigo" (AC 11) ${ }^{9}$. Assim, em vez de se procurar prescrever virtudes como forma de alcance da saúde, como era próprio dos filósofos moralistas antigos, bem como do próprio cristianismo, deverá ser antes, segundo Nietzsche, a saúde peculiar de cada um a ditar as suas também peculiares virtudes. Em crítica explícita à terapia estóica, Nietzsche di-lo muito claramente no já citado aforismo 120 da Gaia Ciência, espécie de síntese de todas as teses que tivemos vindo a enunciar:

A famosa fórmula médica da moral (cujo autor é Aríston de Quios), «a virtude é a saúde da alma», teria, pelo menos, para ser aproveitável, de ser alterada da seguinte forma: «a tua virtude é a saúde da tua alma». Pois uma saúde em si não existe, e todas as tentativas de definir uma coisa desta forma falharam lamentavelmente. (...) Existem, pois, incontáveis saúdes do corpo; e quanto mais se voltar a permitir ao que é único e incomparável que erga a cabeça, quanto mais se desaprender o dogma da "igualdade entre os homens", tanto mais os nossos médicos terão de abandonar também o conceito de uma saúde-normal, juntamente com o de dieta-normal e de curso-normal da doença. E só então deveria ser tempo de reflectir sobre a saúde e a doença da alma e de colocar a virtude peculiar de cada um na sua saúde - a qual, seguramente, numa determinada pessoa poderia ter o aspecto do contrário da saúde numa outra. (GC 120)

É curioso verificar como, mais de cem anos após a morte de Nietzsche, começam agora a surgir as primeiras tentativas de reformulação da definição oficial de saúde, no sentido, precisamente, da sua relativização e individualização. ${ }^{10}$ Compreende-se, com efeito, cada vez melhor o carácter individual de cada saúde particular e, portanto, as deficiências e limitações de uma definição que se pretenda universal. A ser definível, o conceito de saúde deverá, pois, no mínimo, admitir uma amplitude e margens suficientes para abarcar em si todos os casos possíveis, incluindo alguns daqueles que, actualmente, ainda seriam considerados como um desvio à regra e, portanto, como doença. Tal equivaleria, precisamente, ao abandono da tal regra de

9 Cf. o exemplo que Nietzsche dá de Cornaro em CI Os Quatro Grandes Erros 1.

10 Cf. por exemplo BIRCHER \& WEHKAMP (2006, pp. 44-77).

Estudos Nietzsche, Curitiba, v. 5, n. 2, p. 257-286, jul./dez. 2014 
"normalidade" - a "saúde normal", a "dieta normal", o "curso normal da doença" - de que Nietzsche nos fala no último aforismo citado. ${ }^{11}$

O problema que imediatamente se nos coloca é, porém, o da ausência de um critério legítimo de aferição de saúde e doença, uma vez destruídos os critérios tradicionais e mesmo a possibilidade de uma definição (universal) alternativa. Enquanto os actuais teóricos da medicina ainda se debatem quanto ao estabelecimento de eventuais novos critérios, importa-nos, antes de mais, tentar compreender de que forma poderá Nietzsche resolver o problema, sendo certo que não apenas usa constantemente as categorias de saúde e de doença como critérios de valor, como se pressupõe que a saúde seja uma das metas, senão $a$ meta do seu filosofar. Não nos dando Nietzsche uma resposta clara e directa a esta questão, procuraremos encontrá-la nos fundamentos da sua própria antropologia. A exploração da hipótese da vontade de poder parece-nos, a este respeito, particularmente fértil e esclarecedora, ao mesmo tempo que permitirá, num primeiro momento, compreender as razões da inadequação, de um ponto de vista nietzschiano, da actual definição de saúde.

\subsection{A Saúde de uma Vontade de Poder}

À semelhança dos filósofos morais antigos com uma concepção terapêutica da prática da filosofia, como os epicuristas ou os estóicos, também Nietzsche parece fazer apelo à natureza para determinar a regra daquilo que poderá constituir a saúde de um indivíduo, bem como de um povo, de uma época ou de uma cultura. Porém, onde Epicuro vira um corpo que procura pura e simplesmente o prazer e onde os estóicos encontraram uma alma com aspiração à excelência e, portanto, à virtude, Nietzsche descobre como princípio fundamental de tudo o que vive a vontade de poder, cujo objectivo não é outro senão o poder e a expansão do poder. ${ }^{12} \mathrm{Abstraindo} \mathrm{da}$ questão do estatuto ontológico da vontade de poder e considerando-a, para os presentes propósitos, como (pelo menos) um instrumento interpretativo utilizado por Nietzsche para dar conta da natureza da vida e dos processos

11 Precisamente esta ideia de "normalidade" institucionalizada seria, como se sabe, um dos principais elementos da crítica de Foucault à psiquiatria. Cf. em particular FOUCAULT (1989, p. 67; 2003; 2004, p. 95).

12 Cf. por exemplo BM 36. Cf. também BM 13; AC 6; FP 1885 38[12]; FP 1887/88 11[111]. 
envolvidos em qualquer existência humana e nas bases do qual constrói aquilo a que podemos chamar uma antropologia, consideremos sucintamente o que significa descrever o mundo e, por consequência, o homem como, primária e essencialmente, vontade de poder. ${ }^{13}$

Uma primeira implicação, de resto espelhada em todo o pensamento de Nietzsche, é a ausência absoluta de qualquer entidade estável, fixa, imutável ou eterna na natureza: conceber o mundo como vontade de poder significa, precisamente, compreender o mundo como um fluxo interminável de criação, destruição, evolução, mudança e transformação, por sua vez produzido por uma luta eterna entre forças (vontades) diversas e em oposição, que não lutam senão pelo seu próprio crescimento, a sua própria expansão e a sua própria supremacia sobre todas as demais. Segue-se que tudo o que existe no mundo são, na verdade, relações ("tudo é vontade contra vontade" (FP 1886/875[9])), ou, por outras palavras, que tudo o que existe tem uma identidade relacional, não sendo pensável em isolamento ou abstracção do contexto e do jogo de forças em que está inserido. ${ }^{14}$ Note-se que, neste contexto, a possibilidade de um poder absoluto se encontra, desde logo, excluída: ainda que cada força aspire ao domínio sobre todas as outras forças e pretenda, por isso, tornar-se absoluta, o facto de haver sempre outras forças com precisamente o mesmo objectivo determina que o poder seja sempre relativo, limitado e, portanto, meramente de grau.

Que a força mais fundamental da existência seja, por outro lado, uma vontade de poder e, portanto, de expansão, de superação, de violentação, de "apropriação, ofensa, domínio do estranho e do mais fraco, repressão, dureza, imposição de formas próprias, incorporação e (...) exploração" (BM 259) é, por sua vez, a grande inovação de Nietzsche relativamente à compreensão dominante de Schopenhauer ou Darwin da vida como uma simples vontade de auto-preservação ou uma luta pela conservação em vida, respectivamente, pelo que a vontade de poder pode ser entendida como um contra-conceito contra a "vontade de vida" schopenhaueriana,

13 Não pretendemos aqui apresentar uma análise exaustiva de todos os aspectos e problemáticas envolvidos na hipótese nietzschiana da vontade de poder, mas apenas salientar os aspectos fundamentais que determinarão a distância nietzschiana relativamente à concepção tradicional de saúde. Sobre a vontade de poder cf. em particular MÜLLER-LAUTER (1971, p. 10 ss.) e RICHARDSON (1996).

14 Cf. STEGMAIER (2011, p. 168 ss.).

Estudos Nietzsche, Curitiba, v. 5, n. 2, p. 257-286, jul./dez. 2014 
ou a "luta pela existência" de Darwin. ${ }^{15}$ Tal como ensina Zaratustra, de acordo com o "segredo" que "a própria vida" lhe revelou,

Seguramente que não encontrou a verdade quem disparou contra ela a fórmula «vontade de existência»: esta vontade - não existe! Pois aquilo que não existe não pode querer, e aquilo que existe, como poderia ainda querer a existência!

Agora: onde existe vida, existe também vontade; só que não é uma vontade de vida, mas sim - assim te ensino - vontade de poder! Há muitas coisas que aquele que vive valoriza mais do que a própria vida; mas a partir da própria valorização fala - a vontade de poder! — (ZA Da Vitória Sobre Si Próprio)

Quer isto dizer que a vida, por si mesma, não é suficiente, nem constitui o objectivo de nenhum ser vivo, mas é antes um instrumento que se joga numa luta por aquilo a que Nietzsche chama "poder", quer dizer, "por 'mais' e 'melhor' e 'mais depressa' e 'mais frequente”” (FP 1885 34[208]). A luta pela existência não seria, assim, senão uma "excepção" e, na verdade, a expressão de uma vontade de poder degenerada, uma vez que "a luta grande e pequena gira por todo o lado em torno do domínio, do crescimento, da expansão, do poder" (GC 349). Tal não significa, porém, que a vontade de poder seja uma apologia das forças brutas da natureza ou uma ameaça à ordem estabelecida na cultura ou civilização. Ao interpretar o mundo como vontade de poder, Nietzsche está simplesmente a apontar para o facto de todas as relações entre seres vivos e, portanto, também entre os homens, serem relações de poder e por poder, sem que, porém, esta luta por poder se tenha de manifestar através de uma mera violentação, exploração ou aniquilação do outro. No contexto da cultura, estas forças brutas da natureza são necessariamente cultivadas, transformadas e espiritualizadas, assumindo novas formas, como, por exemplo, a da competição pela superioridade ou excelência num plano moral, intelectual, científico ou artístico. Neste sentido, podemos dizer que longe de se opor à cultura, a vontade de poder esclarece o seu desenvolvimento e está mesmo na base da sua eventual auto-superação ou elevação futura. ${ }^{16}$

15 Cf. por exemplo GC 349; BM 13: "Os fisiologistas deveriam reflectir antes de considerar o impulso de autoconservação como o impulso cardinal de um ser orgânico. Acima de tudo, aquilo que é vivo quer manifestar a sua força - a própria vida é vontade de poder -: a auto-conservação é apenas uma das consequências indirectas e mais frequentes disso."; FP 1875 12[22]; FP 1882/83 5[1]; FP 1885 34[208]; FP 1888 16[86].

16 Cf. HATAB (2008, pp. 13-14).

Estudos Nietzsche, Curitiba, v. 5, n. 2, p. 257-286, jul./dez. 2014 
Uma última característica desta concepção do mundo que nos importa frisar é que esta luta por poder se joga eternamente sem qualquer outro propósito que não, justamente, o da auto-superação, domínio e supremacia de cada vontade relativamente a si mesma e a todas as demais, pelo que se segue a ausência de um qualquer propósito, intenção, ou finalidade, de uma qualquer teleologia, e mesmo de qualquer lei ou regra transcendente à natureza: a natureza é "demasiado imbecil, cega e cruel" (FP 1875 9[1]), o seu carácter é "caos para toda a eternidade" (GC 109) e se algo nela for "necessário" e "previsível", não é porque tenha leis fixas e pré-determinadas, mas precisamente porque elas lhe faltam. ${ }^{17}$ Uma concepção oposta ou simplesmente diferente seria ainda, segundo Nietzsche, um mero reflexo de "sombras de Deus" remanescentes, pelo que esta concepção do mundo e da vida não é senão, na verdade, a versão totalmente desdeificada ou "naturalizada" da natureza.

Aplicada ao homem, esta total desdeificação da natureza resultará, como facilmente se adivinha, numa concepção absolutamente naturalizada do ser humano, de acordo com a qual o homem não se distancia ou distingue de outros seres vivos senão por uma diferença de espécie ou de grau. Como qualquer outro animal ou ente natural, o homem é, com efeito, também ele um organismo, isto é, de acordo com a compreensão nietzschiana, uma unidade na qual um conjunto de forças (instintos, impulsos, afectos e paixões) coexiste, numa luta permanente pelo seu fortalecimento e supremacia sobre todas as demais. Note-se que cada força luta por si mesma e ao serviço dos seus próprios interesses e objectivos, mas cada força é também da maior importância para todas as outras, uma vez que é precisamente a resistência, ou a superação da resistência, que permite que cada uma delas se fortaleça e expanda o seu poder. A luta e a guerra são, pois, condições necessárias em qualquer organismo, sendo que uma completa imobilidade significaria a sua destruição. Tal como sucede à macro escala da cultura, também no homem esta luta constante entre as forças que o constituem se apresenta como a condição de possibilidade do seu fortalecimento e eventual auto-superação, razão pela qual qualquer tentativa de erradicação ou supressão de uma determinada parte da sua complexidade pulsional se revelaria, segundo Nietzsche, absolutamente prejudicial. ${ }^{18}$

17 Cf. BM 22. Cf. também GC 109; GM II 12; FP 1881 11[157]; FP 1881 11[205]; FP 1885 38[12].

18 Cf. HH II AS 83, A 425, GC 326, CI A Moral como Contra-Natureza 1, entre outros. 
Enquanto espelho do que acontece no mundo, como um todo, nada no homem é estável, fixo ou permanente, mas antes se encontra num fluxo constante de evolução, transformação e mudança. É por este motivo que, no universo nietzschiano, se encontram absolutamente excluídas quaisquer concepções substancialistas ou essencialistas do homem, bem como qualquer concepção dualista, que encontrasse na "alma", não só um domínio isolado, independente e soberano relativamente ao corpo, mas ainda o resíduo da identidade, subjectividade ou carácter de um sujeito: pensar o homem como organismo implica pensá-lo como um todo, e como um todo cujo princípio unificador é o corpo; uma identidade, a existir, será sempre a identidade de um corpo, da mesma forma que o conceito de "alma", a ser mantido, só fará sentido se compreendido como uma parte do corpo, totalmente dependente dele e subordinada aos seus comandos. ${ }^{19}$ Dada a natureza do corpo ou organismo humano pensado como vontade(s) de poder, esta unidade ou "identidade" nunca será fixa, estável ou inalterável, mas necessariamente mutável, dinâmica e evolutiva, dependente do jogo de forças que nele se joga continuamente e, portanto, das diferentes configurações, relações de poder e, principalmente, hierarquias que, de cada vez, se vão estabelecendo entre a multiplicidade de forças que o constituem. ${ }^{20}$

Daqui se seguem três consequências de extrema importância no que diz respeito à concepção nietzschiana de saúde, que procuraremos explicitar nos três pontos que se seguem, antes de retomarmos a questão de saber até que ponto ou em que medida faz sentido, num mundo compreendido como vontade de poder, falar de saúde e doença na ausência de um critério de aferição universal.

\subsubsection{O Primado da Saúde do Corpo}

Uma primeira consequência desta concepção do mundo e da vida é, evidentemente, a abolição da distinção entre "saúde do corpo" e "saúde da alma", ou, mais concretamente, a denúncia de todos os discursos promovedores de uma "saúde da alma" como algo de independente, superior ou mesmo condicionador da "saúde do corpo" - estratégia que, como se sabe, se encontra

19 Cf. em especial A 119; GC 354; BM 3, 191; ZA, Dos Desprezadores do Corpo.

20 Cf. por exemplo FP 1884 27[27], FP 1885/86 2[87]. 
nos fundamentos mais básicos, quer das terapias filosófico-morais, como as dos estóicos ou epicuristas, quer do representante máximo da terapia religiosa, o cristianismo. No centro de qualquer uma destas terapias está, com efeito, a procura de um tratamento ou correcção (no caso das primeiras), ou mesmo de salvação ou redenção (no caso do cristianismo) da alma, enquanto essência daquilo que o indivíduo propriamente é e, como tal, ponto de partida e de chegada para qualquer terapia da existência humana. Exceptuando o caso de Epicuro, o corpo é absolutamente negligenciado ou desprezado por qualquer uma destas terapias, passado para segundo plano, como mero suporte da alma, ou mesmo caluniado e sacrificado, em todos os casos em que se considere que as suas exigências são obstáculos impeditivos do alcance da felicidade, da tranquilidade da alma ou da bem-aventurança cristã.

Foi, porém, precisamente por ter desprezado o corpo, que Nietzsche considera o cristianismo "a maior desgraça da humanidade" (CI Incursões de Um Extemporâneo 47) e o ideal ascético, no qual se poderia facilmente incluir qualquer uma das terapias anteriores, "o verdadeiro flagelo na história da saúde do homem europeu” (GM III 21). Com efeito, a partir do momento em que se percebe que o homem é um organismo e, portanto, um "corpo e nada mais" (ZA Dos Desprezadores do Corpo), do qual a alma, se se quiser manter a distinção, não será senão uma pequena parte, totalmente dependente dele e a ele subordinada, facilmente se deduz que não existe tal coisa como uma "saúde da alma", pensada em independência e muito menos em contraposição à "saúde do corpo", uma vez que o estado da "alma" será sempre e necessariamente influenciado e determinado pelo estado do corpo a que pertence. Pela mesma lógica, deverá também ser o corpo o ponto de partida para qualquer terapia, e a "saúde do corpo" o seu maior propósito: se tanto a saúde como a doença da alma dependem da saúde ou doença do corpo, qualquer "saúde da alma” terá sempre de ser uma consequência da "saúde do corpo" e de ter esta como sua pré-condição (cf. GC 120; FP 1887 9[121](80)).

Que a "saúde do corpo" seja a pré-condição para a "saúde da alma" e o ponto de partida de qualquer terapia significa, por sua vez, que é a partir de um trabalho ou cultivo ao nível do corpo e da complexidade de instintos, impulsos e afectos que o constituem que uma verdadeira saúde, da "alma" e do corpo, pode ser alcançada. Nietzsche compara este trabalho à arte de um jardineiro que cultiva o seu jardim, por oposição às práticas de excisão ou extirpação de instintos e paixões que caracterizavam os anteriores terapeutas 
da alma: longe de se dever eliminar qualquer instinto, paixão ou afecto, estes devem antes ser cultivados, transformados, refinados, espiritualizados, isto é, mantidos mas transfigurados criativa e produtivamente em novas formas e configurações que permitam a expansão da vontade, promovam o florescimento do organismo e, muito em particular, intensifiquem os instintos fundamentais da vida e do poder. ${ }^{21}$ Sendo este o pressuposto básico de qualquer "moral saudável" (CI A Moral Como Contra-Natureza 4), ele é também a condição de possibilidade da saúde do corpo e, portanto, da saúde da "alma" e mesmo do "espírito". ${ }^{22}$

\subsubsection{O Equilíbrio do Desequilíbrio}

Uma segunda consequência, mais genérica, prender-se-á com a compreensão daquilo que poderá constituir esta "saúde do corpo", sendo certo, no entanto, que existem "incontáveis saúdes do corpo" (GC 120). Independentemente das diferenças naturais e necessárias de caso para caso, de indivíduo para indivíduo, uma objecção óbvia à definição oficial e corrente de saúde ter-se-á já, por esta altura, tornado evidente: se o homem pode ser descrito como vontade de poder e se em tudo o que é dominado pela vontade de poder reina a luta, a guerra, o movimento, a evolução, a mudança e a transformação, é evidente que a saúde não poderá, num universo nietzschiano, constituir um estado de alguma forma estável ou permanente, e muito menos um estado de equilíbrio pacífico entre todas as componentes do organismo. Pelo contrário, a saúde (bem como a doença) exprime-se, também ela, de forma relacional, designando o estado fisiológico de um organismo na sua relação consigo próprio e com o exterior. Assim, num organismo saudável, que se encontre em plena harmonia com a sua natureza, o objectivo deverá ser sempre o seu crescimento, a sua expansão, o seu fortalecimento e contínua auto-superação, podendo mesmo, em determinadas circunstâncias, pôr em risco a sua auto-conservação. Pelo contrário, uma vontade de paz, de tranquilidade, de equilíbrio e de estabilidade, onde é inversamente o instinto

21 Cf. A 174, 382, 560, GC 17, CI A Moral como Contra-Natureza 1-4, FP 1885 37[12]. Cf. WOTLING (1995: 205-210); CONSTÂNCIO (2013: 114-115, 178).

22 Sobre a interligação entre as saúdes do corpo, da alma e do espírito cf. STEGMAIER (2012, pp. 184-191, 602-604).

Estudos Nietzsche, Curitiba, v. 5, n. 2, p. 257-286, jul./dez. 2014 
de auto-conservação que domina, designa para Nietzsche um sintoma de cansaço, de esgotamento e, justamente, de doença, na medida em que contraria o processo natural do organismo. Tal como descreve na Gaia Ciência,

Querer preservar-se é expressão de um estado de necessidade, uma limitação do verdadeiro instinto fundamental da vida, que aspira a uma expansão de poder e que nesta vontade frequentemente põe em causa e sacrifica a auto-preservação. (...) na natureza não é a necessidade que domina, mas sim a abundância e o desperdício, até ao absurdo. A luta pela vida é apenas uma excepção, uma restrição temporária à vontade da vida; a luta grande e pequena gira por todo o lado em torno do domínio, do crescimento, da expansão, do poder, de acordo com a vontade de poder, que, justamente, é a vontade da vida. (GC 349)

$\mathrm{Na}$ medida em que considera o estado óptimo do organismo (isto é, a sua saúde) como um estado de mero "bem-estar" a todos os níveis, em que o organismo simplesmente mantém o seu funcionamento habitual e livre, desimpedido de qualquer obstáculo e, em particular (ainda que não só), desimpedido de qualquer doença, a definição oficial de saúde revela-se ainda, como se percebe, herdeira da concepção dominante de Darwin ou Schopenhauer, segundo a qual a vida é, primária e fundamentalmente, uma luta pela própria existência ou manutenção em vida, isto é, pela sua própria auto-preservação ou auto-conservação. No caso das terapias filosóficas da Antiguidade, a contradição é ainda mais grave, na medida em que não apenas se concebe a saúde como um estado de paz e tranquilidade, como se a identifica ainda com esse estado último de completude e plenitude que seria a "felicidade". Num mundo entendido como vontade de poder, porém, não só se encontra absolutamente excluída a possibilidade de alcance de um tal estado último absolutamente livre de obstáculos e resistências, como um tal estado seria, na verdade, altamente indesejável, na medida em que implicaria um corte radical com a tensão mais essencial de qualquer ser vivo para o seu crescimento, a sua expansão, o seu fortalecimento e a sua auto-superação e, portanto, para a discórdia, a luta, a guerra e o conflito eternos com forças contrárias e adversárias. 


\subsubsection{A Dissolução da Antinomia entre Saúde e Doença}

Uma terceira e última consequência segue-se directa e imediatamente da anterior. Tal como qualquer força precisa de resistências, obstáculos e forças adversárias para se manifestar e, através da sua superação, se tornar maior, mais forte e expandir o seu poder, também a saúde necessita do seu contrário para se fortalecer, se robustecer e se renovar continuamente. Segue-se que, ao contrário daquilo que é comummente aceite e mesmo expresso na definição oficial de saúde, a doença não só não é erradicável, como é mesmo indispensável para a boa constituição e desenvolvimento de uma verdadeira saúde. Muito longe, portanto, de constituir um estado de paz ou equilíbrio, do qual se encontrasse terminantemente excluída a doença e que pudesse ser definitiva ou mesmo provisoriamente alcançado, a saúde designa antes um processo dinâmico ininterrupto, que não só tem de envolver continuamente a doença, como deve envolvê-la e até mesmo desejá-la, enquanto maior instrumento ao serviço da sua própria auto-superação e expansão. ${ }^{23}$

Note-se que a própria antinomia entre saúde e doença deixa, num universo nietzschiano, de fazer sentido: ainda que sejam, de facto, forças opostas e adversárias, saúde e doença fazem parte de um mesmo processo, pelo que, no limite, não existe tal coisa como uma "saúde" ou uma "doença" consideradas em isolamento ou independência uma da outra. Longe de serem entidades separadas e em oposição, saúde e doença devem antes ser consideradas como graus de uma mesma realidade, pelo que, na verdade, nunca nos encontramos completamente saudáveis ou doentes, mas antes sempre e necessariamente, relativamente saudáveis, relativamente doentes (cf. FP 1888 14[119]).

Não havendo, pois, saúde que não se constitua na relação e por relação à doença, é evidente que, para Nietzsche, o sinal distintivo da saúde não poderá nunca ser a ausência ou a eliminação da doença, mas antes o tipo de relação que o organismo estabelece com ela. Sendo a doença omnipresente em qualquer existência, e a própria vida um combate perene

23 Cf. por exemplo CI Máximas e Dardos 8: "O que não me mata torna-me mais forte"; NW Epílogo 1: "E no que diz respeito à minha longa enfermidade, não lhe devo eu indescritivelmente mais do que à minha saúde? Devo-lhe uma saúde superior, uma saúde que se torna mais forte com tudo o que não a destrói!" Esta ideia de uma dialéctica fundamental entre saúde e doença viria a ser desenvolvida por CANGUILHEM (1978), cujo pensamento sobre a saúde e a doença se aproxima extraordinariamente do de Nietzsche. Cf. a este respeito CHERLONNEIX (2008).

Estudos Nietzsche, Curitiba, v. 5, n. 2, p. 257-286, jul./dez. 2014 
e permanente entre saúde e doença, um indício de saúde será, pois, desde logo, a aceitação, não passiva ou resignada mas antes activa e combativa, do patológico em qualquer existência. Por outras palavras, um organismo dir-se-á saudável, não porque não exista qualquer réstia de doença em si, mas porque sabe lidar de forma activa, combativa e afirmativa com a doença que (necessária e permanentemente) existe em si. Como veremos, quanto maior for a capacidade de aceitação e superação da doença, maior será também o nível de saúde do indivíduo. Muito longe de procurar evitar, eliminar ou combater a doença em absoluto e definitivamente, a saúde nietzschiana procurará, pois, ao invés, elevar o jogo e a tensão com ela ao seu nível mais fértil, arrojado e promissor.

\subsection{Um Novo Critério de Saúde}

Fazendo um pequeno resumo dos pontos essenciais acima assinalados, percebemos que, segundo Nietzsche e contra a definição oficial e corrente de saúde, a saúde não é, em primeiro lugar, um estado de equilíbrio que pudesse ser definitiva ou mesmo provisoriamente alcançado, mas sim um processo dinâmico constante, que implica uma constante evolução e transformação de estados, nenhum dos quais podendo ser considerado de pura saúde. Por outro lado, a doença revela-se omnipresente em qualquer existência humana, pelo que este processo dinâmico a que chamamos saúde é, antes de mais, um processo de luta constante contra a doença. Por não haver estados puros de saúde ou de doença, a saúde não se pode distinguir pela ausência completa do seu suposto contrário, a doença, mas sim e apenas pela sua relação com ela. Enquanto força contrária a doença revela-se, na verdade, da maior importância para a constituição de uma verdadeira saúde, uma vez que é através da sua aceitação e superação que a saúde se pode tornar mais forte, rica e profunda. Longe de ser evitada e eliminada, a doença deve, pois, inclusivamente ser bem-vinda e procurada, enquanto maior instrumento ao serviço da elevação, fortalecimento e exponenciação da saúde.

Este é, em poucas palavras, o resultado da transvaloração nietzschiana do conceito de saúde. Como já seria de esperar, dada a compreensão do carácter individual de cada saúde, Nietzsche não nos oferece nenhuma definição universal alternativa, que pudesse corrigir e substituir a antiga, pelo que permanece a questão de saber, afinal, através de que critério pode 
Nietzsche avaliar a saúde ou doença de um indivíduo, de uma cultura ou de um povo, ou que saúde terá em vista quando, enquanto médico da cultura, proclama a necessidade de uma terapia e almeja o alcance da sua saúde. O critério é, na verdade, consequência directa da concepção nietzschiana de saúde e, assim, facilmente dedutível a partir dos pontos acima assinalados. Num fragmento póstumo de 1885, Nietzsche descreve-o da seguinte maneira:

Saúde e morbidez (Krankhaftigkeit): sejamos cautelosos! O critério continua a ser a eflorescência do corpo, a elasticidade, a coragem e a alegria do espírito - mas naturalmente também a quantidade de doença (Krankhaftem) que ele consegue suportar e superar: que consegue tornar saudável. (FP 1885/86 2[97]) ${ }^{24}$

Nietzsche parece, pois, estabelecer o seu critério sobre dois factores combinados: por um lado, a força, a robustez, a energia, a coragem, a ousadia de um organismo; por outro lado, a sua capacidade para suportar e superar a doença. Os dois factores complementam-se e condicionam-se reciprocamente: quanto mais forte, robusto, enérgico e dinâmico for um organismo, maior será a sua capacidade de suportar e superar a doença, e quanto maior for a sua capacidade de suportar e superar a doença, mais forte, robusto, enérgico e dinâmico se tornará o organismo. Pela mesma lógica, um organismo será tanto mais saudável quanto mais e maiores forem as doenças que é capaz de aceitar, incorporar e superar.

Este é um critério que Nietzsche não reserva apenas para os homens, mas aplica a tudo aquilo que seja passível de ser avaliado segundo um critério de saúde ou de doença. Em qualquer caso, a pedra de toque será sempre a avaliação da quantidade de doença - que, num sentido lato, engloba não apenas todo o tipo de patologias em sentido estrito, mas ainda o vasto leque de obstáculos e resistências que podem surgir na existência, bem como ainda toda a dor e sofrimento a ela associados - que um organismo consegue não só aguentar, mas ainda pôr ao seu serviço e utilizar em seu proveito - seja este organismo um homem, uma cultura, um povo, uma época ou uma sociedade. ${ }^{25} \mathrm{E}$ se é verdade que a doença, a dor, o sofrimento, as adversidades são necessárias e omnipresentes em qualquer

24 Cf. também A 202; FP 1887 10[118](234): “— avalio o poder de uma vontade de acordo com a quantidade de resistência, dor, tortura que ela consegue suportar e transformar em seu proveito (...)."

25 Cf. A 202: “(...) ainda nenhum pensador teve a coragem de medir a saúde de uma sociedade ou indivíduo de acordo com a quantidade de parasitas que conseguem suportar (...).” 
existência, também é verdade que os organismos não lhe reagem todos da mesma maneira e, em particular, nem todos possuem esta capacidade de os aceitar e superar activamente. Existem, com efeito, pelo menos dois tipos de reacção ou atitude perante a doença, compreendida no seu sentido mais lato: ou se reage de uma forma absolutamente passiva, se sofre de uma forma resignada ou ressentida, se protesta contra a sorte e a própria vida e se procura protecção contra todos os possíveis riscos ou agravantes do sofrimento, provocando assim um significativo enfraquecimento das forças vitais e do sentimento de poder, ou, pelo contrário, se assume uma atitude de luta activa e afirmativa, de combate enérgico e criativo contra o sofrimento e de procura de novas experiências e desafios às suas próprias capacidades, através dos quais o organismo progressivamente recupera as suas forças e confiança, tornando-se cada vez mais robusto, saudável e capaz de enfrentar eventuais adversidades e doenças futuras.

A estas duas modalidades de confronto com a doença, a dor ou a adversidade, correspondem, igualmente, duas atitudes perante a existência, que Nietzsche claramente tipifica ao longo de toda a sua obra. No primeiro grupo, caracterizado pelo ressentimento, a decadência, o pessimismo, o niilismo inclui-se com particular destaque o cristianismo, esse "produto doentio e decrépito da décadence" (AC 19), bem como toda a cultura moderna e respectivos representantes, como Schopenhauer ou Wagner; ao segundo grupo, e precisamente devido à sua "inclinação intelectual para o duro, o terrível, o mau, o problemático da existência, a partir do bem-estar, de uma saúde transbordante, de uma plenitude da existência" (NT Ensaio de Autocrítica 1), pertencem, acima de tudo, os gregos da época trágica, mas também a filosofia pré-socrática, a aristocracia guerreira de que Nietzsche nos fala no primeiro ensaio da Genealogia da Moral, ou ainda figuras como Júlio César ou Goethe.

Note-se que este é um critério intrinsecamente relacional e absolutamente individual. Quer dizer, e em conformidade com a tese nietzschiana relativamente à impossibilidade de definir a saúde "em si", não existe um estado do organismo que, em abstracto, se possa dizer saudável, para todos os indivíduos e de uma forma universal. A única coisa que existe são diferentes relações do organismo com a doença, entre as quais umas se provam mais saudáveis do que outras. Em geral, e conforme já referido, um organismo será tanto mais saudável quanto maior for a sua capacidade de aceitar, suportar e superar a doença, sendo que o ponto máximo de saúde 
será atingido no limite máximo da tensão entre o saudável e o patológico, isto é, no alcance daquele limite máximo de doença que o indivíduo ainda é capaz de aguentar e utilizar em seu proveito. Este ponto máximo é, porém, absolutamente dependente de cada indivíduo e não aferível de uma forma geral e universal, pelo que, dependendo de cada organismo, um indivíduo pode ser tão saudável quanto outro, mesmo suportando um número mais reduzido de doença, desde que dessa forma seja alcançado o limite máximo da sua força, isto é, do seu poder. Por outras palavras, um organismo será dito supremamente saudável quando conseguir alcançar o máximo de sentimento de poder, de acordo com o princípio interpretativo básico da vontade de poder, segundo o qual "todo o animal (...) aspira instintivamente a um optimum de condições favoráveis, sob as quais possa descarregar completamente a sua força e atingir o seu máximo de sentimento de poder" (GM III 7).

Em estreita conexão com o jogo entre saúde e doença, este sentimento de poder ou "o poder de uma vontade" é, por sua vez, aferido de acordo com "a quantidade de resistência, dor, tortura que ela consegue suportar e transformar em seu proveito" (FP 1887 10[118](234)), ou seja, de acordo com o último fragmento citado, com a quantidade de doença que consegue aguentar e transformar em propulsor da sua própria saúde (cf. FP 1885/86 2[97]). O ponto máximo de sentimento de poder de cada vontade é, por sua vez, extremamente variável e dependente de cada organismo pelo que cada uma terá o seu, com características e aspectos variados, com condicionantes e limites próprios e com a configuração própria de cada organismo particular, razão pela qual, para retomar o nosso ponto inicial, existe um número incontável de saúdes, só aferíveis de um ponto de vista estritamente pessoal, particular e individual.

\section{A Grande Saúde}

Depois de tudo o que foi exposto relativamente à concepção nietzschiana de saúde, impõe-se agora necessariamente a pergunta quanto à peculiaridade daquilo a que Nietzsche chamou "grande saúde". O que distingue, afinal, esta grande saúde das outras, a que poderíamos chamar "pequenas", vulgares ou mesmo normais? Estabelecerá Nietzsche, de facto, uma diferença conceptual entre dois tipos de saúde, ou tratar-se-á a "grande" apenas de uma versão superlativada, de um nível quantitativa e/ou 
qualitativamente superior relativamente à "pequena"? Ou será a utilização ocasional do adjectivo "grande" apenas um recurso estilístico, um mero artifício de retórica, que deixa intacto o conteúdo, já analisado, da noção nietzschiana de saúde?

Nietzsche utiliza o adjectivo "grande" de forma bastante frequente nos seus textos, muitas vezes no seu sentido habitual, corrente, mas outras vezes, normalmente em itálico, também com um sentido próprio, peculiar. Quando é este o caso, Nietzsche parece pretender, em primeiro lugar, desviar o conceito da sua compreensão comum, habitual (está a referir-se ao sen próprio conceito, e não àquele que é vulgarmente adoptado); em segundo lugar, maximizar ou superlativar o conceito, isto é, elevá-lo (na sua própria compreensão) ao seu expoente máximo, quer em termos quantitativos, quer em termos qualitativos ${ }^{26}$; em terceiro lugar, e em relação directa com os dois aspectos anteriores, apontar para algo como o "real" ou "verdadeiro" sentido do conceito, quando devidamente analisado e compreendido, por contraste com aquilo que é a sua compreensão mais habitual. Por último, conforme notou Werner Stegmaier, os "grandes" conceitos de Nietzsche parecem ainda muitas vezes (ainda que nem sempre) possuir uma outra particularidade, nomeadamente, o facto de serem fortalecidos, engrandecidos, potenciados precisamente pelo seu suposto contrário. ${ }^{27}$ Assim se poderá interpretar, por exemplo, a "grande razão" 28 - a razão do corpo, que transforma a "pequena razão", a razão tradicional, em sua ferramenta e instrumento -, o "grande amor" 29 - o de Zaratustra pela humanidade, por exemplo, que é no entanto reforçado por um grande desprezo pela humanidade presente -, a "grande liberdade" ${ }^{30}$ - aquela que é, porém, a mais sobrecarregada de obrigações e de

26 Note-se a amplitude semântica do adjectivo "grande", que, mesmo no seu uso corrente, tanto pode denotar um tamanho, dimensão, volume ou comprimento acima da média, uma longa extensão no tempo, uma forte intensidade, como também maturidade, desenvoltura, importância, influência, dificuldade, gravidade, imponência, qualidade, excelência, ou ainda um elevado grau de determinadas capacidades ou valores morais. Todos estes aspectos parecem fazer parte dos "grandes" conceitos nietzschianos.

27 Cf. STEGMAIER (2008, pp. 110-111; 2011, pp. 183-185; 2012, pp. 168-171).

28 Cf. por exemplo ZA Dos Desprezadores do Corpo; BM 201.

29 Cf. por exemplo ZA Dos Compassivos, Das Tarântulas, Da Virtude que Apouca 3.

30 Cf. por exemplo CE III 8. Cf. também HH I 458; EH CE 3.

Estudos Nietzsche, Curitiba, v. 5, n. 2, p. 257-286, jul./dez. 2014 
uma "pesada culpa" (UB III 8) -, a "grande seriedade"31 - que se constitui, precisamente, através de uma "paródia" relativamente a tudo o que até então fora considerado sério -, e também a "grande saúde". Neste sentido, a grande saúde seria então aquela que, longe de ser diminuída, enfraquecida ou destruída pelo seu suposto contrário, a doença, antes seria por ela fortalecida, potenciada, exponenciada. ${ }^{32}$

Note-se, porém, que esta dialéctica entre saúde e doença se encontra já na noção nietzschiana de "simples" saúde, pelo que alguma precaução nos deverá impedir de atribuir e generalizar, à semelhança de Stegmaier, um sentido demasiado específico ou técnico à utilização nietzschiana do adjectivo "grande". Se é certo que este sentido dialéctico pode ser encontrado em todas as expressões acima referidas, também é certo, por um lado, que existem muitas outras utilizações do adjectivo onde não se parece encontrar tal sentido $^{33}$ e, por outro lado, que na maior parte das vezes este mesmo sentido já se encontra na simples noção nietzschiana, com ou sem a adjectivação de "grande" - até porque, dado o seu intuito de dissolver todas as antigas oposições da metafísica, grande parte dos conceitos de Nietzsche já incluem, de facto, este mesmo sentido dialéctico ou esta mesma interacção entre supostos contrários. Assim, e concretizando, não é claro que quando Nietzsche se refere ao "grande amor", à "grande liberdade", ou à "grande saúde" se esteja a referir a algo diferente daquilo que considera, na sua própria concepção, ser realmente o "amor", a "liberdade", ou a "saúde", respectivamente. O que o adjectivo "grande" parece indicar é, de facto, acima de tudo, que se trata da sua própria concepção (por contraposição à corrente), e desta mesma concepção elevada ao expoente máximo da sua potencialidade.

Assim e pelo mesmo motivo, não nos parece acertado procurar distinguir, como Cherlonneix (2002) ou Bilheran (2005), dois tipos de

31 Cf. por exemplo GC 382; EH ZA 2.

32 Para STEGMAIER (2012: 606), a “grande saúde” é, justamente, o exemplo mais plausível para a sua interpretação do sentido dialéctico de "grande" (gross).

33 Parece ser o caso, por exemplo, do "grande sofrimento" (CE III, 7); da "grande decisão" (GM II 24), do "grande meio-dia" (ZA Da Virtude que Oferece 3), do "grande perigo" (GC 318), da "grande paixão" (A 471), da "grande necessidade" (GC 351), da "grande dor” (NW, Epílogo, 1), entre tantos outros. Nas suas obras mais recentes, STEGMAIER (2011, p. 183; 2012, p. 169) admite também a utilização do adjectivo num sentido meramente quantitativo ou qualitativo, pelo que a nossa maior objecção à sua interpretação será o ponto que se segue, nomeadamente, a ideia de que o adjectivo "grande" acrescenta conceptualmente alguma coisa à noção que adjectiva. 
saúde na obra de Nietzsche. De acordo com estes autores, com efeito, seria possível reconstituir, com base no tipo de interacções possíveis entre saúde e doença, uma espécie de tipologia de saúdes e de doenças no pensamento de Nietzsche, da qual, por sua vez, resultariam quatro combinações fundamentais. Do lado da doença, existiria a "doença como fim (la maladie comme fin)" - a doença sem réstia de saúde, irremediável, incurável -, e a "doença como meio (la maladie comme moyen)" - uma doença meramente temporária ou provisória, cuja finalidade seria, na verdade, a promoção da saúde. ${ }^{34}$ Do lado da saúde, teríamos por um lado a "grande saúde", a que os autores chamam "saúde dinâmica (santé dynamique)" - em sentido estrito, a única verdadeira saúde, caracterizada pela dialéctica constante com a doença e a sua capacidade de auto-superação permanente - e, por outro lado, a "saúde de equilíbrio (santé d'équilibre)" (Cherlonneix) ou "saúde conforto (santé confort)" (Bilheran) - próxima da nossa concepção habitual de saúde, enquanto estado (temporário) de equilíbrio não (ainda não ou já não) afectado pela doença e, portanto, livre de qualquer interacção com ela. ${ }^{35}$

Esta interpretação parece-nos, porém, assentar numa contradição de fundo, que, curiosamente, os autores parecem não ver. Nomeadamente, esta interpretação pressupõe que Nietzsche estivesse, na verdade, de acordo com a definição oficial de saúde, complementando-a apenas com um caso excepcional de saúde, que seria então particularmente valorizado e idealizado - isto é, como se de acordo com Nietzsche se pudesse, de facto, falar de um estado de equilíbrio no organismo, caracterizado pela estabilidade, pela harmonia, e pela ausência de qualquer réstia de doença - correspondendo este à saúde mais vulgar -, ao qual depois se pudesse contrapor o caso mais raro e valioso de uma saúde que se constituísse pela luta e pela capacidade de superar permanentemente a doença e assim se fortalecer continuamente a si própria. Ora, conforme procurámos mostrar na secção precedente, justamente, não é assim: se o organismo se encontra governado pela vontade de poder e, como tal, em constante movimento, mudança e transformação; se, por outro lado, saúde e doença não são estados independentes e contrários, mas antes partes de um contínuo em relação permanente de interdependência mútua; se, por último, o organismo não se encontra em circunstância alguma totalmente livre de doença, isto é, de resistências ou obstáculos a combater e a superar

34 Cf. BILHERAN (2005, pp. 41, 48-58); CHERLONNEIX (2002a, pp. 115-126).

35 Cf. BILHERAN (2005, pp. 48-58); CHERLONNEIX (2002a, pp. 83-104). 
- proposições que ambos os autores parecem aceitar -, segue-se então que a possibilidade de algo como uma "saúde de equilíbrio", mesmo que apenas provisória ou temporária, se encontra terminantemente excluída. Conforme já referido, no universo nietzschiano a saúde constitui-se sempre e apenas numa determinada relação - nomeadamente, na relação com a doença -, pelo que se podemos eventualmente, com Cherlonneix e Bilheran, falar de dois tipos de doença (uma incurável, impossível de superar, a outra combatível e, portanto, provisória ou temporária) ${ }^{36}$, o mesmo já não se passa no que diz respeito à saúde, cuja essência ou natureza será sempre e necessariamente a de um processo relacional e dinâmico, constante e interminável. Note-se que, neste sentido, mesmo que o tal estado de equilíbrio fosse possível de alcançar, dificilmente este poderia ser considerado por Nietzsche um estado de saúde, uma vez que a saúde se constitui precisamente na relação, no movimento e na transformação, ou, mais concretamente, pela sua capacidade de aceitar, combater e superar continuamente a doença. Num estado onde não houvesse doença, resistências ou obstáculos a ultrapassar, a própria possibilidade de constituição de saúde estaria, pois, desde logo vedada.

Negar que existam, no pensamento de Nietzsche, diferentes tipos de saúde, não significa, porém, afirmar que todas as saúdes sejam iguais, nem tão-pouco que não exista qualquer forma de distinguir diferentes ocorrências de saúde. Não sendo esta diferença seguramente de tipo (isto é, de natureza ou de essência), as saúdes distinguem-se, porém, naturalmente, por uma diferença de nível, ou de grau, sendo precisamente para este aspecto que a expressão nietzschiana "grande saúde" parece apontar. Neste sentido, a grande saúde conservará precisamente as mesmas características da saúde, por assim dizer, normal, mas elevá-las-á ao limite da sua possibilidade, isto é, à sua forma mais maximizada, superlativada ou exponenciada, tanto quantitativa como qualitativamente. A sua peculiaridade consistirá, assim, por um lado, na sua extraordinária força, plasticidade, persistência, audácia e robustez, e, por outro lado, na excepcional violência da dialéctica que aguenta com o seu "contrário", a doença. Por outras palavras, a grande saúde

36 Note-se que mesmo esta distinção entre dois tipos de doença, apesar de admissível, não deixa de ser também algo artificial: à partida, não existem doenças incuráveis ou superáveis em si mesmas, ou, dito noutros termos, o seu carácter curável ou incurável não advém de si próprias, da sua natureza, ou da sua essência, mas sim do seu portador, da sua capacidade de as superar ou não, isto é, do seu grau de saúde, pelo que, em última análise, tanto a saúde como a doença são intrinsecamente relativas e relacionais.

Estudos Nietzsche, Curitiba, v. 5, n. 2, p. 257-286, jul./dez. 2014 
será aquela que elevará ao máximo a tensão e o combate com a doença, permitindo-se as maiores e mais graves doenças, mantendo a sua capacidade de as superar e, assim, de se superar também a si mesma, num movimento contínuo de auto-regeneração, fortalecimento e superação. Se pensarmos no jogo permanente entre saúde e doença como um arco com graus de tensão variáveis, a grande saúde seria esse ponto de tensão máxima, em que se acumulou a quantidade máxima de doença sem que, porém, o elástico tenha ainda rebentado. ${ }^{37}$

Tal como a saúde mais vulgar, a grande saúde não é, pois, algo que se possa adquirir definitivamente ou conquistar de uma vez por todas e para sempre, mas antes uma constante dinâmica de ganhos e de perdas, de sucessos e de retrocessos, algo que "não apenas se tem, mas que constantemente se adquire e tem de se adquirir, porque também constantemente se abandona, tem de se abandonar!...” (GC 382) É precisamente esta dialéctica entre saúde e doença, entre o adoecer e o convalescer, que, encontrando-se no centro da noção nietzschiana de saúde, é levada ao extremo na grande saúde. Quanto maior for a doença adquirida e mais difícil for a recuperação, maior será a saúde alcançada depois da sua superação. Quem, por conseguinte, quiser alcançar esta grande saúde, deverá precisamente expor-se ao perigo e enfrentar as maiores doenças e dificuldades, precisamente para que as possa depois ultrapassar e, assim, transformar em seu próprio proveito. Descobrir a quantidade de doença que se consegue suportar e superar é, precisamente, a perigosa experiência da grande saúde: como Nietzsche escreve num fragmento póstumo, "aquilo que destruiria os homens mais delicados pertence aos meios estimulantes da grande saúde" (FP 1885/86 2[97]). Os portadores desta grande saúde são pois, nas palavras de Nietzsche, "talvez mais corajosos do que seria razoável”, mas também "mais saudáveis do que se quereria consentir, perigosamente saudáveis, sempre de novo saudáveis” (GC 382), regressando de cada vez, de cada convalescença, de cada recuperação da doença, "como novos, com novas peles, mais caprichosos, mais maliciosos, (...) mais infantis e, no entanto, cem vezes mais subtis do que alguém alguma vez foi." (GC Prefácio 4)

A grande saúde pode, pois, ser descrita como uma particular força, robustez e plasticidade do organismo, por uma singular vontade de vida, de crescimento e de expansão, que por sua vez predispõe o seu portador

37 Agradeço a Antonio Edmilson Paschoal a sugestão desta perspicaz analogia. 
para o perigo, o risco, a aventura e o desafio dos seus próprios limites. Tal experimentação e desafio constantes dos seus limites abre, por sua vez, um conjunto enorme de novas possibilidades e perspectivas, razão pela qual Nietzsche lhe parece atribuir particular importância no que diz respeito ao conhecimento e, assim, aos novos filósofos, que antevê (cf. GC 382). Uma total explanação da relevância e do papel filosóficos da grande saúde no pensamento de Nietzsche exigiria, naturalmente, uma análise cuidada de cada um dos passos a ela dedicados, tarefa que não poderemos levar a cabo aqui. Em todo o caso, uma tal associação não nos deverá soar surpreendente se pensarmos, por um lado, que Nietzsche caracteriza os filósofos precedentes como profundamente doentios e marcados pelo niilismo corrente ${ }^{38}$, circunstância que os tornou essencialmente veículos e promotores da doença e, por outro lado, que no pensamento de Nietzsche é precisamente aos filósofos do futuro que cabe a tarefa de transmutação e criação de novos valores, através dos quais seja possível a superação do niilismo e uma verdadeira reabilitação da cultura ocidental.

Para que possam cumprir esta tarefa, porém, os novos filósofos terão de possuir em si a complexidade que lhes permita, num primeiro momento, a profunda incorporação e vivência do niilismo e de tudo o que nele é nocivo, prejudicial e doentio, mas, num segundo momento, também a força, a robustez e a plasticidade que lhes permita superá-lo em si mesmos e dar o impulso a interpretações e valores contrários, bem como a coragem para promover uma mundividência profundamente afirmativa. Por outras palavras, os novos filósofos terão de ter a capacidade de possuir em si, simultaneamente, tanto a doença, elevada ao seu grau mais extremo de gravidade, como a saúde, num grau ainda mais elevado, que lhes permita superar a doença, transformando-a ainda em algo positivo e a seu favor. Foi justamente a esta complexidade que Nietzsche chamou "grande saúde". E é precisamente porque só ela parece permitir a superação do grau de doença em causa no niilismo da cultura ocidental, dando ainda o impulso para a criação de novos valores e a promoção de uma verdadeira afirmação existencial que ela se configura como o "novo meio" (GC 382) ou a "pressuposição fisiológica fundamental” (EH ZA II) para a execução do seu projecto de reabilitação, reforma ou elevação de toda a cultura ocidental.

38 Cf. por exemplo GC Prefácio 2. Sobre este tema cf. FAUSTINO (2011). 


\section{Referências}

AHERN, Daniel R. (1995), Nietzsche as Cultural Physician, University Park, Pennsylvania, The Pennsylvania University Press.

BILHERAN, Ariane (2005), La Maladie, Critère des Valeurs chez Nietzsche. Prémices d'une Psychanalyse des Affects, Paris, L'Harmattan.

BIRCHER, Johannes \& WEHKAMP, Karl-H. (2006), Das ungenutzte Potential der Medizin. Analyse von Gesundheit und Krankheit zu Beginn des 21. Jahrhunderts, Zürich, rüffer \& rub.

CANGUILHEM, Georges (1978), On the Normal and the Pathological, Dordrecht, D. Reidel Publishing Company.

CHERLONNEIX, Laurent (2002a), Nietzsche: Santé et Maladie, l'Art, Paris, L'Harmattan.

CHERLONNEIX, Laurent (2002b), Philosophie Medicale de Nietzsche: la Conaissance, la Nature, Paris, L'Harmattan.

CHERLONNEIX, Laurent (2008), "Après Nietzsche et Canguilhem", in: A. FAGOT-LARGEAULT, C. DEBRU, M. MORANGE (dir.) \& Hee-Jin HAN (ed.), Philosophie et Médecine. En Hommage à Georges Canguilhem, Paris, Vrin, 2008, pp. 35-47.

CONSTÂNCIO, João (2013), Arte e Niilismo. Nietzsche e o Enigma do Mundo, Lisboa, Tinta-da-China.

FAUSTINO, Marta (2010), "Nietzsches Umkehrung des Gesundheitsbegriffes und die «große Gesundheit»", in: C. PIAZZESI, G. CAMPIONI \& P. WOTLING (eds.), Letture della Gaia scienza - Lectures du Gai savoir, Pisa, ETS, 2010, pp. 219-233.

FAUSTINO, Marta (2011), "Philosophy as a 'Misunderstanding of the Body' and the 'Great Health' of the New Philosophers", in: J. Constâncio \& M. Branco (eds.), Nietzsche on Instinct and Language, Berlin/ Boston, Walter de Gruyter, 2011, pp. 203-218.

FAUSTINO, Marta (2014), Nietzsche e a Grande Saúde. Para uma Terapia da Terapia, Tese apresentada para cumprimento dos requisitos necessários à obtenção 
do grau de Doutor em Filosofia, Faculdade de Ciências Sociais e Humanas da Universidade Nova de Lisboa.

FOUCAULT, Michel (1989), Résumé des cours 1970-1982, Conférences essais e leçons du Collège de France, Paris, Julliard.

FOUCAULT, Michel (2003), Le pouvoir psychiatrique. Cours au Collège de France, 1973-1974, Paris, Gallimard.

FOUCAULT, Michel (2004), 'Je suis un artificier', in: R.-P. DROIT (ed.), Michel Foucault, entretiens. Paris, Odile Jacob, 2004, pp. 89-135.

HATAB, Lawrence (2008), Nietzsche's On the Genealogy of Morality: An Introduction, Cambridge, Cambridge University Press.

LONG, Thomas (1990), Nietzsche's Philosophy of Medicine, in: NietzscheStudien, 19, 1990, pp. 112-128.

MÜLLER-LAUTER, Wolfgang (1971), Nietzsche: Seine Philosophie der Gegensätze und die Gegensätze seiner Philosophie, Berlin, Walter de Gruyter.

NIETZSCHE, Friedrich (1980), Sämtliche Werke: Kritische Studienausgabe (KSA), 15 Bände, ed. G. Colli \& M. Montinari, München/ Berlin/ New York, Walter de Gruyter.

PASLEY, Malcolm (1978), "Nietzsche's Use of Medical Terms”, in: M. PASLEY (ed.), Nietzsche: Imagery and Thought - A Collection of Essays, London, Methuen, 1978, pp. 123-158.

RAZAC, Olivier (2006), La Grande Santé, Paris, Climats.

RICHARDSON, John (1996), Nietzsche's System, New York/ Oxford, Oxford University Press.

SCHIPPERGES, Heinrich (1975), Am Leitfaden des Leibes. Zur Anthropologik und Therapeutik Friedrich Nietzsches, Stuttgart, Ernst Klett Verlag.

SCLIAR, Moacyr (2007), História do conceito de saúde, in: Physis, 17(1), 2007, pp. 29-41.

STEGMAIER, Werner (2008), "Schicksal Nietzsche? Zu Nietzsches Selbsteinschätzung als Schicksal der Philosophie und der Menschheit (Ecce Homo, Warum ich ein Schicksal bin 1)", in: Nietzsche-Studien, 37, 2008, pp. 62-114. 
STEGMAIER, Werner (2011), Nietzsche zur Einführung, Hamburg, Junius, 2011. STEGMAIER, Werner (2012), Nietzsches Befreiung der Philosophie. Kontextuelle Interpretation des V. Buches der Fröhlichen Wissenschaft, Berlin/ Boston, Walter de Gruyter.

WOTLING, Patrick (1995), Nietzsche et le Problème de la Civilisation, Paris, PUF.

\section{Marta Faustino}

Investigadora do Instituto de Filosofia da Nova (IFILNOVA/FCSH), e-mail:msffaustino@gmail.com

Recebido: 22/02/2015

Received: 02/22/2015

Aprovado: 25/04/2015

Approved: 04/25/2015 